\title{
Developing Community and Social Cohesion through Grassroots Bridge Building: An Exploration
}

\section{By Margaret Harris and Patricia Young*}

A Paper prepared for submission to the journal 'Policy and Politics', May 2008. Revised following reviewer comments November 2008

Word length: 7936 including abstract, text, tables and references

*The authors are grateful for the assistance of Jane Andrews Ph.D; Chung-Dao Pan, Ph.D. and Selena Teeling in preparing this paper.

Contact person for this paper:

Margaret Harris, Ph.D

Professor Emeritus Aston University and

Visiting Professor, Birkbeck, University of London

18A Deacons Hill Road, Elstree, Herts, WD6 3LH

Tel. 07860907779

Email m.e.harris@aston.ac.uk 


\section{Developing Community and Social Cohesion through Grassroots Bridge Building: An exploration}

\section{Paper Abstract}

In the context of the UK public policy goal to increase community and social cohesion, this paper explores the nature of local 'bridge-building'; activities intended to increase inter-personal contacts between diverse ethnic, faith and nationality groups. We draw on earlier research in a range of fields to develop the bridge-building concept and present findings from a study which identified community-level projects with bridge-building as a specific aim. We show the range of groupings involved, the activities encompassed and their organisational features. We consider the actual and potential contribution of local bridge-building to cohesion in the light of earlier research and our own study.

\section{Key Words}

cohesion; bridge-building; ethnicity; faith, immigration

\section{Introduction}

In the context of an increasingly diverse population and amid politicians' concerns about the implications of diversity for solidarity, trust and civil society (Attwood et al, 2001; Pennant, 2005), there has been a public policy drive in the UK to build social and community 'cohesion' ( Burnett, 2007; Cantle, 2001; DCLG, 2006; Gilchrist, 2004). The ideological and practical assumptions underpinning the cohesion agenda continue to be fiercely debated by academics and activists (Bagguley and Hussain, 2008; Flint, 2007; Flint and Robinson, 2008; McGhee, 2003).

Nevertheless, the trend of recent policy is clear: established ideas of encouraging respect for difference (often referred to as 'multiculturalism) are now seen as needing to be complemented by policies which actively encourage interaction and mutual accommodation across identity group boundaries (Cheong et al, 2007; Denham, 2002; Modood, 2007; Watson, 2000). There has been a particular focus on increasing inter-personal relationships between people of different faiths, ethnicity and country of origin and on encouraging them to work together to develop shared values and achieve common goals (CIC, 2007; Faulkner, 2004; HM Treasury, 2007).

This paper explores the extent are which these policy goals are implementable. To what extent do 
they accord with research knowledge about how people in a diverse society behave collectively at the grassroots in their streets and neighbourhoods?

Although some research attention has been given to 'peace and reconciliation' education and similar initiatives at national and international levels (Acheson et al, 2006; Gidron et al, 1999; Salomon and Nevo, 2002), and although 'inter-faith dialogue' as one particular cross-group activity is widely advocated (Holden, 2006), there are two areas in which research is still sparse. First, activities which cross identity group boundaries at the 'grassroots' level have been given very little research attention; even though many public policies assume their existence (DCLG, 2006; DCLG, 2008; Home Office, 2004; IDeA, 2006) and even though the media regularly carry stories about exemplary initiatives which are said to be successfully building links across faith and ethnic divides or between settled populations and new immigrants. Second, although there is now an emerging literature on grassroots networking involving recent immigrants, including refugees and asylum seekers (for example, Beirens et al, 2007; Daly, 2007; Wilson and Zipfel, 2008), few researchers have moved beyond a focus on relationships across faith group boundaries (Alif Alef UK, 2005; Schachter, 1992). Studies have generally not addressed directly the fact that, in the UK as in many other countries, there are complex overlaps between ethnic, nationality and faith groupings (Barekh, 2000; Modood, 2007; Vertovec, 2006). Indeed, the complexity of these overlaps between traditional 'categories' is constantly increasing with successive waves of immigration from different regions.

In this paper, then, we explore what is known about 'bridge building activities' or 'BBAs'; activities which bridge faith, ethnic and nationality divides at the grassroots; activities based in local geographical areas (eg streets and neighbourhoods) and/or organised as community projects or associations. We first identify and draw together the hitherto disparate academic literature which relates in some way to the bridge-building idea. We then set out the findings from an empirical study in three English urban areas, of community-level projects with bridge building as a specific aim. We show the range of groupings involved, the range of goals and activities encompassed and how activities are organised. We conclude by considering the reality of grassroots bridge- 
building in the UK at present and by discussing the implications of our findings for achieving the public policy goal of community and social cohesion.

\section{Civil Society Theories}

One underpinning for the bridge-building idea is provided by theories which present civil society as a space within which a broad range of interest and identity groups can establish associations reflecting their multiple and distinctive cultural values but also within which conflict and opposition can be mediated peacefully (Eberly, 2000; Walzer, 1995). As Allen and Cars (2001:2205) say, a "flourishing civil society is important because it creates numerous opportunities for members of different cultural communities to meet....as people become used to each other, cross-cultural understanding and trust are built up, including the skills to negotiate and live with unresolved differences". Thus interactions within the associations and groupings of civil society are seen as the foundation for peaceful, trusting and cohesive societies (Forrest and Kearns, 2001; Hirst, 1993).

The concept of 'deliberative democracy' extends the idea within civil society theory of pluralism accompanied by open discussion of difference. The role of inter-group dialogue in helping people to adapt to living in a heterogeneous society has been emphasised by several authors (eg Porter, 2000; Schoem et al, 2001) and was taken up in an influential report on 'multi-ethnic' Britain (Barekh, 2000) which argued (p53) that "intercultural dialogue ... shows respect for minority viewpoints, involves people in decisions that affect them, deepens understanding between communities and leads to realistic and widely acceptable decisions".

Related to civil society theory, social capital theory, as propounded by authors including Halpern (2005) and Putnam et al (1993) also provides concepts which are relevant to the idea of bridgebuilding between diverse groupings (Cheong et al, 2007). Especially relevant is the concept of 'bridging social capital'; "relationships that cross demographic divides of class, age and ethnicity" (Leonard and Onyx, 2003:191). These kinds of relationships are seen as qualitatively different 
from the 'bonding social capital' which is built up through interaction within identity groups, friendships networks and families. Some authors (eg CIC, 2007; McGhee, 2002) have suggested that bonding social capital is a necessary precursor to bridging social capital because individuals who are secure in their own group identity are more tolerant of those who are different from themselves. However, this view is challenged by studies which have found that those tightly bound into family or identity groups networks are more likely to hold hostile attitudes to people from identity groups different from their own (Dench et al, 2006; Forrest and Kearns,2001). Thus, it is argued, strong intra-group networks, which can be so important in providing support and a sense of belonging to individuals, may also have implications which are less conducive to the cohesion of broader society.

Another limitation to the building of bridging social capital identified in earlier studies is that people need to be positively encouraged and motivated to interact with 'different' people if bridging social capital is to be developed and sustained (Daley, 2007; SHM, 2007). Specific opportunities need to be created for inter-group engagement and participation and, even then, successful interactions may require careful facilitation and the driving enthusiasm of individual activists (CIC, 2007; Dench et al, 2006; Weisinger and Salipante, 2005).

Several authors suggest that in order to create links and promote interaction between diverse people, one should focus on shared visions, shared tasks and 'superordinate goals' (King, 2004; Tal-Or et al, 2002; Taylor \& Moghaddam, 1994 ). However, Ashman et al (1998), Gilchrist (2004) and Leonard and Onyx (2003) have all pointed out that this kind of coming together of previously separated groupings requires not only facilitating mechanisms, but also leaders skilled in acting as intermediaries across cultures.

\section{Research by Social Psychologists}

Ideas on bridge building grounded in studies of civil society and social capital are largely supported by social psychology research. Thus Berry (1997) suggests that integration (as distinct from 
assimilation, segregation or marginalisation) is the most successful acculturation strategy; characterised by "interest in both maintaining one's original culture, while in daily interactions with others...while at the same time seeking to participate as an integral part of the larger social network" (p9). But success also requires supportive national policies and attitudes. Research in Northern Ireland, for example, showed the need for "sufficient political stability....and welfare state policies and structures [which] promote equality of access to social and economic resources" (Acheson et al, 2006: 122).

Allport's seminal text on 'The Nature of Prejudice' (1954), suggested that it is lack of contact between groups that can lead to prejudice and conflict. Conflict arises, he suggested, from lack of information about the other group and from lack of opportunities to obtain information. However, this 'contact hypothesis', which appears to have been influential in the development of the cohesion policy agenda (Cantle, 2001; Flint and Robinson, 2008), has been criticised for its assumption that prejudice is caused by ignorance about the out-group and for the assumption that contact will inevitably lead to the discovery of common ground and improved inter-group relations (Hewstone \& Brown, 1986; Vincent, 2008). Also, several authors, while not totally rejecting the hypothesis, have suggested that certain conditions must apply if inter-group contact is to lead to improved understanding. Amir (2002), for example, says that casual contact is insufficient to bring about change in attitudes. Van Dick et al (2004:211) confirm the importance of more intimate contact, observing that "intergroup friendship is regarded as an ideal contact experience".

An alternative reason for hostility between people of different groups is provided by social identity theory. This suggests that people seek to derive positive self-identity from their group membership (Brown, 1988; Taylor \& Moghaddam, 1994) and view the group as "an entity qualitatively different from the sum total of all the individuals comprising it" (Suleiman, 2004: 326). This can lead people to exaggerate inter-group differences and intra-group similarities; triggering stereotyping (Jackson 1996). Attempts to mitigate the impact of inter-group hostility using the cognitive theories and concepts of social psychology are particularly evident in the fields of conflict resolution and peace education. The definition of reconciliation offered by Jeong and Lerche (2002:329), for example, is 
to "change the relational dynamics in a conflict system by creating new perceptions and exploring a new shared experience". The creation of cross-cutting ties and the fostering of super-ordinate goals (as described above) are also suggested (Kriesberg, 1999). However, the conflict resolution literature also emphasises the difficulty of generalising psychological or psycho-dynamic changes in an individual or small-group, to a larger social relationship (Jeong and Lerche,1999). Broader conditions, such as power and injustice, may make reconciliation more difficult; sustainable reconciliation requires change at structural as well as interpersonal levels.

\section{Grassroots Bridge Building}

Several authors have identified local (geographical) communities as being a key locus for interactions across identity group boundaries (CULF, 2006; Gilchrist, 2004). As Clayton (2004:7) says, it is often at the level of streets and neighbourhoods that "identities and ideas of the ethnic 'other' are....reconstituted on a daily basis through contestations and negotiations of inclusion, belonging and membership....redefining racial classification through people's individual experiences of multicultural engagement (and non-engagement)". Similarly Thomas (2007:451) refers to the importance of "safe spaces for contact and negotiation" where perceptions can be changed "through contact and dialogue with people from other backgrounds". Amin (2002) concurs that "the microcultures of place" (p967) and the "prosaic negotiations and transgressions" (p971) of everyday street-level life can foster understanding between groups. However, like Alif Alef UK (2005) and Jeong and Lerch (1999), and in line with the arguments about the benefits of 'deliberative democracy' mentioned earlier, Amin emphasises that such interactions need to include explicit discussion of difference - 'discursive clashes' - if transformational change is to occur and people's perspectives are to change. And Dench et al (2006) point out that attempts to emphasise the common interests of different groups at the local level can be confounded by competition between those groups for scarce public resources such as social housing and urban regeneration grants.

Another limitation on local geographical areas as sites of bridge-building is provided by the 
research evidence referred to in the discussion above of social capital, which suggests that bridging activities need positive fostering; they are rarely something that people will freely engage in without encouragement. There are both internal barriers (for example, fear and cultural and language difficulties) and external barriers (for example, social and geographical segregation) (SHM, 2007). A study of community relations in a refugee settlement area found that groups left to themselves remained within their own 'comfort zones' (Daley, 2007). The role of community and grassroots associations in removing barriers of this kind and in positively fostering opportunities for inter-group interaction has been noted by Smith (1997).

\section{Bridge Building and Social Cohesion}

Our drawing together of disparate earlier research relevant to bridge-building indicates that the idea of encouraging interpersonal links across identity group boundaries has been addressed from a number of disciplinary and theoretical perspectives and using a range of concepts. Authors have also addressed the political, social and psychological barriers to such inter-group contacts and suggested ways in which they might be overcome in practice.

Despite ongoing debate about some key concepts, the body of literature reviewed here suggests a number of themes which provide initial ideas about how BBAs might contribute to implementation of the cohesion public policy goal. First, authors seem to agree that social cohesion requires that people interact not only within their own identity groups but also across the boundaries of those groups; these kinds of interpersonal interactions are seen to be foundational for reducing prejudice and inter-group hostility and for building societies of peaceful coexistence. Second, authors point out the need for inter-group contacts to be positively encouraged and organised; sustained contacts and relationships across identity-group divides require organisational frameworks and committed leadership and facilitation. Third, cross-group interactions can be encouraged by using techniques which develop new and shared goals, identities and experiences. Fourth, it seems that social cohesion requires a supportive social, economic and public policy environment. 
Yet there are a number of aspects of bridge-building which have been little addressed so far. First, very few authors have discussed the bridge building idea with specific reference to grassroots levels of activity. Second, the organisational frameworks for bridge building activities have been largely ignored, even though knowledge about how BBAs can be effective is of prime concern to community activists and public policy makers. Third, although ethnic difference has been studied, at least by implication, when talking about group identities and boundaries, less attention has been paid by researchers to faith group and nationality differences. Even fewer have acknowledged the overlapping nature in practice of groupings by ethnicity, faith and country of origin.

Our own study therefore aimed to focus on grassroots bridge-building activities across ethnic and/or faith and/or country of origin groupings. We were particularly interested to map the occurrence of BBAs within local geographical areas and to discover their organisational features

\section{The BBA Study}

We selected for study three urban local authority areas in different geographical areas of England. Each is highly diverse according to data on ethnic origin and faith but they differ as to the nature of their diversity profiles and their local political environments (Figure One).

Figure One - The Three Study Areas

\begin{tabular}{|l|c|c|}
\hline $\begin{array}{l}\text { Local Government } \\
\text { Area }\end{array}$ & $\begin{array}{l}\text { Population 2001 } \\
\text { Census }\end{array}$ & $\begin{array}{l}\text { \%Population non-white } \\
\text { ethnic groups }\end{array}$ \\
\hline Birmingham & 977,000 & 30 \\
\hline Oldham & 217,000 & 14 \\
\hline Tower Hamlets & 196,000 & 49 \\
\hline
\end{tabular}

Source: National Statistics, 2007 
Although it had the lowest overall proportion of non-white ethnic groups, Oldham has a high degree of residential segregation of black and minority ethnic (BME) groups, as well as a history of racist political activity and recent civil disturbances fuelled by race tensions (Amin, 2002; Bagguley and Hussain, 2008; Cantle, 2001). It is also notable for the fact that most of its BME population are from Pakistani or Bangledeshi origin. Seventy three per cent of Oldham's population declared themselves to be Christian and the next largest religion group was Muslim (11\%). By contrast, Tower Hamlets, which has a much higher proportion of non-white groups overall, has more of a mix of different non-white ethnic groups. $33 \%$ of the population is of Bangladeshi origin but the remainder of the BME population ( $16 \%$ of the total) comes from a wide range of country backgrounds. Thirty nine percent of the population of Tower Hamlets declared themselves to be Christians and $36 \%$ were Muslim. Birmingham has $59 \%$ of its population who are Christians and $14 \%$ who are Muslims. It is the only one of the three study areas that has substantial proportions of religions other than Christianity and Islam; in Birmingham 3\% of the population are Sikh and $2 \%$ Hindu. Historically it was one of the first areas in England where 'race' was an overt factor in local politics (in the 1960s), but it has generally been free of public disturbances apart from recent local conflicts between some BME groups (Vulliamy, 2005).

Since there is no official or published source of secondary data about bridge-building at the grassroots, we had to gather data step by step. We designed the study such that the initial mapping stage comprised telephone and face to face interviews with key local informants; people with in-depth local knowledge and understanding in each of the areas. In addition we contacted numerous agencies and organisations which might potentially have information about grassroots bridge building activities; including local authority departments, schools; health trusts; regeneration teams, local police forces, third sector infrastructure organisations, headquarters of faith groups, university departments and special initiatives focused on faith or ethnicity eg the Faith Based Regeneration Network (FbRN, 2007) We also searched relevant databases including Guidestar, a specialist third sector database. Finally, notices were placed on websites and in relevant professional journals, alerting practitioners to the research and asking them to contact the study 
team should they know about any relevant local activities.

In making our contacts, and in keeping with the identified gap in earlier research, we used a broad working definition of grassroots bridge-building: local and neighbourhood-based activity intended to build bridges between people of different ethnic and/or faith backgrounds and/or between people from different countries of origin. We also included intentionality in our working definition in order to set some boundaries around activities to be examined; since incidental bridge-building (interpersonal links across divides which appear to have happened as a byproduct of an activity which had other goals) is extensively claimed by voluntary and community groups but hard to verify or evaluate.

Over a three month period, using networking and snowballing techniques, we were able to identify a total of 160 BBAs across the three areas; 80 (50\%) were in Birmingham and roughly $25 \%$ were in each of Oldham and Tower Hamlets. Each of the 160 identified BBAs was invited to participate in a telephone interview during which members of the research team completed a questionnaire to capture information about key characteristics of the BBA, including: information about the person being interviewed; goals and history of the BBA; focus (inter-ethnic / inter-faith / both / other types of bridge building); activities (type, frequency, location and management); status (whether a project, charity, community association etc); and funding. We achieved 127 usable completed questionnaires; 48 from Birmingham; 32 from Oldham; and 37 from Tower Hamlets. In the presentation and analysis of findings set out in the next section, we mostly present our results by reference to the total population of 127 BBAs. However, for each question, we did also analyse the findings area by area and, where appropriate, we refer to significant found differences between areas.

We cannot claim that our study population of BBAs, as a total, or area by area, is necessarily representative of all grassroots BBA activity in England. However, we believe that by studying three areas with differing histories and demographic profiles, we have maximised the chances that our findings broadly reflect current trends in grassroots bridge-building activity in England. 


\section{Survey Findings}

Nearly $40 \%$ of the 127 BBAs were well established, having started in 2002 or before that. Very few started in 2003 or 2004 but there was a very noticeable increase in start-ups during 2005 and 2006 (44\% in total started in one of those years). And although the information for 2007 applied to only the first six months of the year, it seems that new BBAs were still forming in substantial numbers. The surge in start-ups since 2005 is probably attributable in part to a public policy climate increasingly supportive of attempts to build social and community cohesion; a climate reflected in new funding initiatives including, most notably, the Faith Communities Capacity Building Fund which was announced in January 2005 as part of a strategy to 'increase race equality and community cohesion' (Home Office, 2005: title page); and the Connecting Communities Plus Grants Programme which began in April 2006 (CDF, 2007). The hypothesis that the recent surge in start-ups is attributable to national environmental factors is confirmed by the findings of similar start up patterns in each of the three areas studied (Table 1). 


\begin{tabular}{|c|c|c|c|c|c|c|c|}
\hline & 2007 & 2006 & 2005 & 2004 & 2003 & $\begin{array}{l}2002 \\
\text { and } \\
\text { before }\end{array}$ & Total \\
\hline TH (n) & 4 & 11 & 8 & 0 & 1 & 13 & 37 \\
\hline Within area & $10.8 \%$ & $29.7 \%$ & $21.6 \%$ & $0.0 \%$ & $2.7 \%$ & $35.1 \%$ & $100.0 \%$ \\
\hline Oldham (n) & 3 & 11 & 7 & 3 & 2 & 16 & 42 \\
\hline Within area & $7.1 \%$ & 26.2 & $16.7 \%$ & $7.1 \%$ & $4.8 \%$ & $38.1 \%$ & $100.0 \%$ \\
\hline B'ham (n) & 4 & 10 & 9 & 2 & 3 & 20 & 48 \\
\hline Within area & $8.3 \%$ & $20.8 \%$ & $18.8 \%$ & $4.2 \%$ & $6.3 \%$ & $41.7 \%$ & $100.0 \%$ \\
\hline \multirow[t]{2}{*}{ Total } & $\overline{11}$ & 32 & 24 & 5 & 6 & 49 & 127 \\
\hline & $8.7 \%$ & $25.2 \%$ & $18.9 \%$ & $3.9 \%$ & $4.7 \%$ & $38.6 \%$ & $100.0 \%$ \\
\hline
\end{tabular}

Sig. $=0.916>0.05$

As might be expected in the light of the public policy emphasis on inter-group relationships and cohesion, the majority of our respondents (64\%) said that their BBA was initially driven by a specific vision to build bridges across ethnic or faith groups. Most of the remainder began with the prime motivation of responding to a perceived local need, a more traditional start-up history for voluntary and community organisations.

As regards the stated aims of BBAs, we gave our respondents the opportunity to tell us about as many as they wished, in keeping with the exploratory nature of the study. Within the overall mission of building bridges, we found a very wide range of formal aims and most BBAs had two or more (Table 2). 
Table 2 The Stated Aims of BBAs (multiple-response question)

\begin{tabular}{lrrr}
\hline & Count & Pct of & Pct of \\
& & responses & Cases \\
\hline Social cohesion/social integration & 113 & 18.7 & 90.0 \\
Social contact/social interaction & 109 & 18.0 & 85.8 \\
Mutual learning/mutual understanding & 102 & 16.9 & 80.3 \\
Community development & 96 & 15.9 & 75.6 \\
Citizenship development/skills & 73 & 12.1 & 57.5 \\
Crime reduction & 37 & 6.1 & 29.1 \\
Physical & 28 & 4.6 & 22.0 \\
regeneration/repair/improvement & & & \\
Economic development & 26 & 4.3 & 20.5 \\
Others & 20 & 3.3 & 15.7 \\
\hline Total & 604 & 100.0 & \\
\hline
\end{tabular}

The most often-cited aims were those involving the development of social cohesion and social integration ( $19 \%$ of all responses and $90 \%$ of all BBAs surveyed), and social contact and social interaction ( $18 \%$ of all responses and $86 \%$ of all BBAs). Seventeen percent of responses $(80 \%$ of BBAs) mentioned an aim of mutual learning or mutual understanding and $16 \%$ of responses $(76 \%$ of BBAs) referred to community development aims. More practical and tangible aims such as physical regeneration and crime reduction were less often mentioned. Further analysis of answers to the 'stated aims' question showed that all except 6 of the 127 respondents had given one or more of the first three categories as a stated aim. In other words, $95 \%$ of all the BBAs were aiming at social cohesion and/or social interaction and/or mutual understanding. In fact, we found that 91 (72\%) of all respondents named all three categories as being part of their aims. 
As regards the origin of BBAs, we found that more than one third (35\%) began with a pre-existing third sector organisation expanding its range of activities or extending an existing project to include bridge building. An additional $27 \%$ began from an entrepreneurial initiative taken by a governmental organisation or, more usually, a third sector organisation. Thus about $63 \%$ of all BBAs were originally nurtured by a pre-existing organisational structure of some kind and in some way. However, we also found that $21 \%$ of respondents reported that their BBA was started on the initiative of a single entrepreneurial individual. As might be expected given the fact that so many of our identified BBAs were incubated by a pre-existing organisation, $70 \%$ of BBAs were part of a broader organisation (generally they were seen as a 'project' of that organisation). A further $11 \%$ were part of an organisational consortium and only 24 (19\%) declared themselves to be independent third sector organisations.

Reflecting these organisational arrangements to a large extent (Table 3), 20 BBAs (16\%) were registered charities in their own right and a further $8(6 \%)$ were constituted as community associations; that is, $22 \%$ were formally constituted as independent third sector organisations. Conversely, nearly half (49\%) were part of a registered charity at the time of the telephone survey. The formal status of the remaining 45 BBAs surveyed was varied and sometimes unclear to respondents themselves. Fourteen (11\%) described their BBA as being constitutionally a part of a governmental organisation; for example the local authority, a school, or a health agency. A further $11(9 \%)$ of BBAs were described as 'companies' of some kind. Bridge-building projects do not, it seems, occur solely under third sector auspices. 
Table 3 The Formal Status of BBAs

\begin{tabular}{lrr}
\hline & Frequency & Percent \\
\hline Part of a registered charity & 62 & 48.8 \\
Registered charity & 20 & 15.7 \\
Part of governmental org & 14 & 11.0 \\
Constituted community association & 8 & 6.3 \\
In a partnership & 7 & 5.5 \\
Company & 11 & 8.7 \\
No status/unsure & 5 & 3.9 \\
\hline Total & 127 & 100.0 \\
\hline
\end{tabular}

At the time of the survey, $89 \%$ of BBAs (112) reported being in receipt of some kind of external financial resources or in-kind external support. We used a multiple response question to gauge the range of sources (Table 4). The most frequently reported source of funding was charitable trusts ( $21 \%$ of all responses and $45 \%$ of all BBAs surveyed) followed by grants or contracts from national government or the European Union (13\% of all responses and $28 \%$ of all BBAs) and grants or contracts from local government (12\% of all responses and $27 \%$ of all BBAs). A total of 49 respondents (39\%) reported that their BBA received no funding from any governmental source. Only $9 \%$ of BBAs were receiving donations from individuals although $19 \%$ were receiving support in the form of paid staff time donated by another organisation and $17 \%$ were similarly benefiting from the involvement of volunteers attached to another organisation. 
Table 4 Funding and other resources of 112 BBAs in receipt of any external support (multiple-response question)

\begin{tabular}{lccc}
\hline & Frequency & Pct of & Pct of \\
& & response & cases \\
& & & (112) \\
\hline Grant from charitable trust & 57 & 20.8 & 50.9 \\
Grant/contract from govt or EU special programme & 35 & 12.8 & 31.3 \\
Grant/contract from local authority & 34 & 12.4 & 30.4 \\
Premises from other organisation & 26 & 9.5 & 23.2 \\
Grant/contract direct from a central gov dept & 25 & 9.1 & 22.3 \\
Paid staff from other organisation & 24 & 8.8 & 21.4 \\
Volunteers from other organisation & 22 & 8.0 & 19.6 \\
Grant from voluntary or community organisation & 19 & 6.9 & 17.0 \\
Individual donations/subscriptions & 11 & 4.0 & 9.8 \\
Grant from a business & & & 8.0 \\
Others & 9 & 3.3 & 10.7 \\
\hline Total & 12 & 4.4 & \\
\hline
\end{tabular}

The responses to a question to respondents about the groups involved in their bridge building activities are shown in Table 5. They reflect earlier research which has argued that ethnicity and faith are categorisations which do not necessarily match personal experience of group boundaries or the difficulties in practice of clear categorisation (Amin, 2002). They also reflect the argument that, in the UK at least, faith and ethnicity are in practice overlapping categories (Modood, 2007). Thus only $78(61 \%)$ stated that their BBA was mainly about what was clearly 'inter-ethnic' or 'interfaith' relationships; for example bringing together "Black, Asian and White men" or "working with the Muslim, Christian and Hindu communities". The remainder described the groupings that they 
sought to bring together in a variety of ways and in a variety of combinations.

Particularly interesting was the confirmation of the existence of bridge-building between people of different countries of origin. A total of $25(19 \%)$ of BBAs were either solely concerned with bridging between people from different countries of origin or partially concerned with it. This finding is a reminder that differences in national or country cultures can be as much a source of hostility and low trust as can be faith or ethnicity, although differences of this kind are less frequently mentioned in policy documents. Moreover a common religion does not necessarily tie people together if they come from very different national cultures. For example, Pakistanis and Somalis are generally Muslims but their experiences prior to arriving in Britain have been very different and they differ in cultural norms about the role of women, food, dress, religious observance and so on.

We were also interested that 20 respondents (16\%) described their activities as just 'generally bridge building'; a finding which suggests that the concept of bridge-building and the idea of bridge-building as a grassroots activity are coming to be seen as objectives in their own right.

\section{Table 5 Groupings Targeted by BBAs}

\begin{tabular}{lrr}
\hline & Frequency & Percent \\
\hline Mainly inter-ethnic & 58 & 45.7 \\
Mainly inter-faith & 20 & 15.7 \\
Generally bridge building & 20 & 15.7 \\
Between people from different countries of origin & 12 & 9.4 \\
Inter-ethnic, inter-faith \& between people from & 10 & 7.9 \\
different countries & & \\
Inter-ethnic \& inter-faith & 4 & 3.1 \\
Inter-ethnic and between people from different coun. & 3 & 2.4 \\
\hline Total & 127 & 100.0 \\
\hline
\end{tabular}


There were some differences between the three study areas in the answers to our question about groups involved in BBAs. For example respondents in Oldham and Tower Hamlets were far more likely than those in Birmingham to say that their BBAs were mainly inter-ethnic. And those in Tower Hamlets were more likely to say that their BBAs were mainly inter-faith than those in Birmingham or Oldham. Birmingham respondents were also more likely to describe combinations of groupings involved in their BBAs and much less likely than respondents in Tower Hamlets or Oldham to say that their BBAs were mainly inter-ethnic or inter-faith. These differences may reflect the ethnic and faith profile of the three areas and how faith and ethnicity have been experienced and interpreted in them. Living in a city with a wide variety of immigrant groupings, Birmingham people are perhaps more aware of the tensions that can arise between people from different countries of origin. They are also perhaps less focused on specific boundaries and more focused on the bridge-building idea in general, or on interaction between a variety of groupings. The focus on inter-faith BBAs in Tower Hamlets may reflect the large number of initiatives to build bridges which have been initiated by local Christian churches in that area (CULF, 2006).

We only included within our survey BBAs which were operating at the grassroots; bringing together people across streets and neighbourhoods and/or working as community associations. However, we wanted to gauge the geographical 'reach' of bridge building activities so we asked our respondents where people involved in their BBA mainly came from. Only $22 \%$ of respondents in fact described their BBA as being mainly confined to one neighbourhood and an additional $12 \%$ operated across neighbourhoods. But the percentage that were operating at neighbourhood level in this way (35\%) was less than the percentage which described their BBA as taking place across a local authority area. This may be a function of the receipt of local authority or other kind of governmental funding which encourages groups to look beyond their own immediate geographical area.

We again used a multiple response question when we asked about the specific activities sponsored by the BBAs (Table 6) as we were keen to explore the full range of activities encompassed under the bridge-building umbrella. The most frequently mentioned activities were 
social ( $20 \%$ of all responses and $81 \%$ of all BBAs surveyed); education, training and learning activities (18\% of all responses and $72 \%$ of BBAs); and facilitated dialogue ( $16 \%$ of all responses and $64 \%$ of BBAs). In fact, only four of the 127 respondents did not mention at least one of these activities; and 54 (43\%) mentioned that they did all three. These findings about the popularity of social, educational and dialogue activities are in line with earlier literature in which these three kinds of activities are recorded as widely used in efforts to increase inter-group contacts or achieve conciliation between antagonistic groupings (Amin, 2002: Gilchrist, 2004; Weisinger and Salipante, 2005). The next two most frequently cited activities were sport and visual arts. Sport, especially soccer in the UK, is, it seems, a popular way of bringing together boys and young men. Although some literature suggests that it is important to address sources of conflict directly (eg Alif-Aleph UK, 2005; Barekh, 2000; Schoem et al, 2001) references to faith-based activities or facilitated conflict resolution were comparatively low $(8 \%$ and $6 \%$ of responses respectively and $32 \%$ and $23 \%$ of all BBAs surveyed)

Table 6 Bridge Building Activities (multiple-response question)

\begin{tabular}{lrrr}
\hline & Count & Pct of & Pct of \\
& & response & cases \\
\hline Social activities & 103 & 19.9 & 81.1 \\
Education/training/learning/childcare & 92 & 17.8 & 72.4 \\
Facilitated dialogue & 81 & 15.7 & 63.8 \\
Sport & 52 & 10.1 & 41.0 \\
Visual arts & 50 & 9.7 & 39.4 \\
Religious/faith-based & 40 & 7.7 & 31.5 \\
Facilitated conflict resolution & 29 & 5.6 & 22.8 \\
Renewal/repair/regeneration of physical fabric & 22 & 4.3 & 17.3 \\
Other & 48 & 9.3 & 37.8 \\
\hline Total & & & 100.0 \\
\hline
\end{tabular}


We wanted to be able to distinguish between those BBAs which were essentially one- off or infrequent events (such as fetes or concerts for example) and those which involved frequent and/or regular meetings of participants. Taking together answers which referred to weekly, fortnightly or monthly meetings with those which referred generally to 'regular and frequent' events, the majority of BBAs seemed to be occurring in a consistent and frequent manner (91 or $72 \%)$. This seems, initially, to be surprising given the grassroots nature of the BBAs. However, it becomes less surprising when one takes into account the high proportion of BBAs whose activities were mainly organised by paid staff or paid staff working together with volunteers (58\% and $13 \%$ respectively, a total of $71 \%)$.

\section{The Potential Policy Contribution of Bridge Building Activities}

Our empirical study of grassroots BBAs was intentionally exploratory but it provides, nevertheless, some ideas about the contribution that local BBAs are making, and could make, to implementation of the cohesion policy agenda. Yet it also suggests some reservations about current policy expectations on BBAs.

Although there are no comprehensive records of bridge-building activities as such, snowballing and networking research methods enabled us to identify a plethora of local initiatives in each of the three areas studied; all of them expressly focused on building interpersonal linkages between people of different ethnicities, faith and/or country of origin. The majority owed their start-up and survival to the commitment of local people or local third sector organizations, rather than, for example, government initiatives or encouragement. Moreover, the BBAs we found chose their aims and activities in direct response to perceived local needs and those activities were generally about interaction, mutual learning and community development; that is they were more closely in accord with the cohesion agenda than with other public policies relating, for example, to crime prevention, urban regeneration or combating extremism.

Despite their often informal and very local nature, many of the BBAs were sufficiently aware of the 
cohesion policy agenda to be able to tap into related governmental funding as it became available; an awareness perhaps attributable to the close links which most of them had with more formal third sector organisations. All the same, governmental funding was not a prime source of support for the BBAs; they mostly relied on independent sources such as grants from charitable trusts, volunteer time and the resources of 'partner' organisations. And despite the relatively precarious nature of their resources, we found many BBAs which had managed to sustain themselves for five or more years at the time of the study.

In short, and at least in the three diverse areas we studied, there exists a network of grassroots community groupings focused on building bridges across divides of ethnicity, faith and original nationality. The cohesion public policy agenda is, apparently, broadly in tune with efforts being made voluntarily and independently by ordinary people in their local areas. Moreover, earlier literature suggests that we can expect them to continue to flourish and even expand their activities in the current policy environment which is broadly supportive of their aims.

These positive indicators that the cohesion policy agenda is implementable need to be balanced against other findings from our study and the earlier literature which suggest some caution. For example, our study found a clear preference for social, educational, cultural and sporting activities - shared or 'superordinate' tasks and interests - rather than the more confrontational activities (eg facilitated dialogue) recommended by some social psychologists. We also found that clear categorisations based on ethnicity or faith - which are often reflected in application criteria for public funding - are not necessarily salient at the grassroots level. In some areas major divides are based on country of origin rather than faith or ethnicity and in some areas ethnicity, faith and country of origin are in practice overlapping categories. In some cases, common experiences (eg of refugee status or children attending the same school) are the main foundation for building bridges between people from traditionally divided groupings.

Thus attempts by governments to encourage bridge building at the grassroots will need to be responsive to how local people prefer to do their bridge building and also to how they categorise 
themselves into identity groups. Funding criteria intended to encourage and support local bridge building should be such that there is maximum local discretion about the types of activities to be sponsored, their formal aims, and the groupings between which bridges are to be built; perceptions of the nature of inter-personal divides vary widely within and between areas. Similarly, local ideas about the most appropriate way to build bridges vary. Traditional activities such as dialogue and education are not necessarily preferred approaches; in fact there is a strong preference at the grassroots for building bridges through social activities.

Earlier research shows that positive contacts across traditional divides require a supportive environment if they are to flourish. In seeking to be supportive, policy makers will also need to be responsive to perceptions and preferences at the grassroots.

\section{In Conclusion}

This paper has explored the scope for implementation of the cohesion policy agenda through an examination of earlier academic literature and an empirical study of grassroots bridge-building activities in three diverse English areas. The puzzle of how to foster peaceful societies in which people of diverse backgrounds interact in mutual respect will continue to be of major concern to public policy makers in years to come. Researchers in the future might contribute positively to debates on this question by providing in-depth case studies of local bridge building activities which can complement the kind of mapping exercise reported in this paper and provide information about the range of ways in which bridging can occur independently at the local level. They might also assist policy makers by analyzing the factors which contribute to positive experiences of bridging at the local level and by developing indicators for evaluation of the impact of bridging projects on individual attitudes and behaviour. Finally, academics can continue to provide a critical perspective on the assumptions underpinning complex concepts such as 'cohesion'.

\section{References}


Acheson, N., Williamson, A., Cairns, E., Stringer, M. (2006). Voluntary Action and Community $\underline{\text { Relations in Northern Ireland: A Report of a Research Project Funded by the Community Relations }}$ Council and the Office of First Minister and Deputy First Minister. Coleraine: Centre for Voluntary Action Studies \& School of Psychology

Alif-Aleph UK (2005). A Mapping Report of Positive Contact Between British Muslims and British Jews. London: Alif-Aleph

Allen, J., Cars, G. (2001). Multiculturalism and Governing Neighbourhoods. Urban Studies 38 (12): 2195-2209.

Allport, G. W. (1954). The Nature of Prejudice. MA, Addison-Wesley.

Amin, A. (2002). Ethnicity and the Multicultural City: Living with Diversity. Environment and Planning 34 (6): 959-980.

Amir, Y. (2002). 'Contact Hypothesis in Ethnic Relations' in E. Weiner (Ed.) The Handbook of

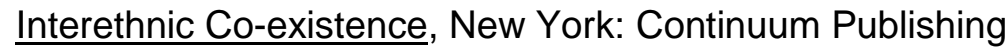

Ashman, D., Brown, L.D., Zwick, E. (1998). The Strength of Strong and Weak Ties: Building Social Capital for the Formation and Governance of Civil Society Resource Organisations. Nonprofit Management and Leadership 9 (2): 153-171.

Attwood, C., Singh, G., Prime, D., Creasey, R. (2001). Citizenship Survey: People Families and Communities. London: Home Office.

Bagguley, B. and Hussain, Y. (2008) Riotous Citizens: Ethnic Conflict in Multicultural Britain Ashgate 
Barekh, P. (2000). The Future of Multi-Ethnic Britain. Report of the Commission on the Future of Multi-Ethnic Britain. London: Runnnymede Trust \& Profile Books

Beirens, H., Hughes, N., Hek, R. and Spicer, N. (2007) Preventing Social Exclusion of Refugee and Asylum Seeking Children: Building New Networks Social Policy and Society 6 (2): 219-229

Berry, J. W. (1997). Immigration, Acculturation, and Adaptation Applied Psychology: An International Review 46(1): 5-34.

Brown, R. (1988). 'Intergroup Relations' in Hewstone, M., Stroebe, W., Stephenson, G.M., (Eds)

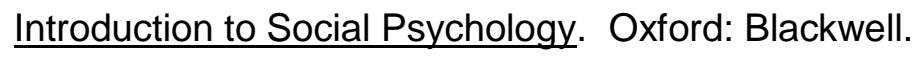

Burnett, J. (2007) Britain's 'Civilising Project': Community Cohesion and Core Values Policy and Politics 35(2): 353-357

Cantle, T. (2001). Community Cohesion: A Report of the Independent Review Team. London: Home Office.

CDF (2007) Connecting Communities Plus, Communities Grants Programme www.cdf.org.uk accessed 15.10 .07

CIC (2007) Our Shared Future London: Commission on Integration and Cohesion

Cheong, P.H., Edwards, R., Goulbourne, H. and Solomos, J. (2007) Immigration, Social Cohesion

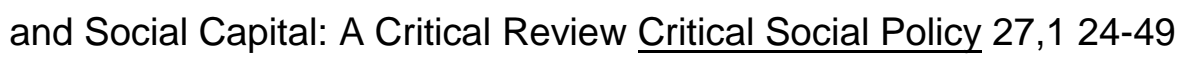

Clayton, J. (2004). The Everyday Politics of the Multicultural City. London: Office of the Deputy Prime Minister \& the Economic and Social Research Council 
CULF (2006) Faithful Cities: A Call for Celebration, Vision and Justice Commission on Urban Life and Faith, London: Methodist Publishing and Church House Publishing

Daley, C. (forthcoming) Exploring Community Connections: A Case Study of Community Relations in a Refugee Settlement Area. Community Development Journal

DCLG (2006). Strong and Prosperous Communities: The Local Government White Paper. Cm 6939 London: Department for Communities and Local Government.

DCLG (2008) Guidance for Local Authorities on Community Cohesion Contingency Planning and Tension Monitoring London: Department for Communities and Local Government

Dench, G., Gavron, K., Young, M. (2006). The New East End Kinship, Race and Conflict London: Profile Books

Denham, J. (2002). Building Cohesive Communities: A Report of the Ministerial Group on Public Order and Community Cohesion. London: Home Office.

Eberly, D. E. (2000). 'The Meaning, Origins and Applications of Civil Society' in Eberly, D.E. (ed) The Essential Civil Society Reader: Classic Essays in the American Civil Society Debate. Maryland ; Rowman \& Littlefield

Faulkner, D. (2004). Civil Renewal, Diversity and Social Capital in a Multi-ethnic Britain. London: Runnymede.

FbRN (2007) About FBRN UK www.fbrn.org.uk accessed 15.10.07

Flint, J. (2007) Faith Schools, Multiculturalism and Community Cohesion: Muslim and Roman Catholic State Schools in England and Scotland Policy and Politics 35(2): 251-268 
Flint, J. and Robinson, D. (2008) Conclusions in Flint, J. and Robinson, D. (eds) Community Cohesion in Crisis? New Dimensions of Diversity and Difference Bristol: Policy Press

Forrest, R., Kearns, A. (2001).Social Cohesion, Social Capital and the Neighbourhood. Urban Studies 38 (12): 2145-2162.

Gidron, B., Katz, S. N., Hasenfeld, Y. (2002). Mobilizing for Peace: Conflict Resolution in Northern Ireland, Israel / Palestine, and South Africa. Oxford: Oxford University Press.

Gilchrist, A. (2004). Community Cohesion and Community Development. Bridges or Barricades, London: Community Development Foundation \& Runnymede Trust

Halpern, D. (2005) Social Capital Cambridge: Polity

Hewstone, M.; Brown, R. (1986). 'Contact is Not Enough: An Intergroup Perspective on the Contact Hypothesis'. In Hewstone, M. and Brown, R. (Eds) Contact and Conflict in Intergroup Encounters. Oxford: Blackwell.

Hirst, P. Q. (1993). Associative Democracy, New Forms of Economic and Social Governance Cambridge:_Polity Press

HM Treasury (2007) The Future Role of the Third Sector in Social and Economic Regeneration: Final Report Cmnd 7189, London: HM Treasury

Holden, A. (2006). The Burnley Project: Evaluating the Contribution of Interfaith Dialogue to Community Cohesion, Lancaster. University of Lancaster.

Home Office. (2004). The End of Parallel Lives? The Report of the Community Cohesion Panel. 
London: Home Office

Home Office (2005) Improving Opportunity, Strengthening Society London: Home Office

IDeA (2006). The Power of Sport: Policy, Sport and Cohesion. London: Innovation and Development Agency

Jackson, S.E. (1996) 'The Consequences of Diversity in Multidisciplinary Work Teams' in West, E., (Ed) Handbook of Work Group Psychology Chichester: John Wiley \& Sons Ltd

Jeong, H., Lerche, C. (1999). 'Research on Conflict Resolution'. In Jeong, H. (Ed) $\underline{\text { Conflict }}$ Resolution: Dynamics, Process and Structure. Aldershot: Ashgate.

Jeong, H., Lerche, C. (2002). Reconciliation and its Social and Political Dimension International Politics 29: 329-339.

King, N. K. (2004). Social Capital and Nonprofit Leaders Nonprofit Management and Leadership 14(4): 471-486.

Kriesberg, L. (1999). 'Paths to Varieties of Intercommunal Reconciliation' in Jeong, H. (Ed) Conflict Resolution: Dynamics, Process and Structure. Aldershot: Ashgate.

Leonard, R., Onyx, J. (2003). Networking Through Loose and Strong Ties: An Australian Qualitative Study Voluntas 14(2): 189-203.

McGhee, D. (2003). Moving to 'our' common ground - a critical examination of community cohesion discourse in twenty-first century Britain. Sociological Review 51 (3): 376-404.

Modood, T. (2007). Multiculturalism: A Civic Idea. Cambridge: Polity Press. 
National Statistics (2007) National Statistics OnLine http:// www.statistics.gov.uk accessed 19.09.07

Pennant, R. (2005). Diversity, Trust and Community Participation in England. London:Home Office.

Porter, E. (2000). 'Participatory Democracy and the Challenge of Dialogue Across Difference' in

Roulston, C., Davies, C. (eds) Gender, Democracy and Inclusion in Northern Ireland. York. Palgrave.

Putnam, R., R. Leonardi, R. Nanetti (1993) Making Democracy Work New Jersey: Princeton University Press

Salomon, G. and Nevo, B. (eds) (2002)_Peace Education: The Concepts, Principles and Practices Around the World. New Jersey: Lawrence Erlbaum Associates

Schachter, Z. M. (1992) Bases and Boundaries of Jewish, Christian and Moslem Dialogue in L.Swidler (ed) Muslims in Dialogue: The Evolution of a Dialogue Lewiston, NY: Edwin Mellen Press

Schoem, D. Hurtardo, S., Sevig, T., Chesler, M., Sumida, S.H. (2001). Intergroup Dialogue: Democracy at Work in Theory and Practice in Schoem, D and Hurtado, S. (Eds) Intergroup Dialogue: Deliberative Democracy in School, College, Community \& Workplace. Ann Arbor: University of Michigan .

SHM (2007). Promoting Interaction Between People from Different Ethnic Backgrounds. London:Commission for Racial Equality.

Smith, D.H. (1997). Grassroots Associations Are Important: Some Theory and a Review of the Impact Literature Nonprofit and Voluntary Sector Quarterly 26(3): 269-306. 
Suleiman, R. (2004).Planned Encounters Between Jewish and Palestinian Israelis: A Social Psychological Perspective Journal of Social Issues 60 (2): 323-337.

Tal-Or, N., Boninger, D., Gleicher, F. (2002). 'Understanding the Conditions and Processes Necessary for Intergroup Contact to Reduce Prejudice' in Salomon, G., Nevo, B. (Eds) Peace Education: The Concepts, Principles and Practices Around the World. New Jersey: Lawrence Erlbaum Associates

Taylor, D., Moghaddam, F.M. (1994). Theories of Intergroup Relations: International Social Psychological Perspectives Connecticut: Praeger

Thomas, P. (2007). Moving on From 'Anti-Racism'? Understandings of 'Community Cohesion' held by Youth Workers Journal of Social Policy 36 (3): 435-455

Van Dick, R., Pettigrew, T., Wolf, C., Castro, V.S., Wagner, U., Christ, O., Petzel, T., Jackson, J.S. (2004).Role of Perceived Importance in Intergroup Contact Journal of Personality and Social Psychology 87(2): 211-227

Vertovec, S. (2006). The Emergence of Super-Diversity in Britain. Working Paper No 25. Oxford: Centre on Migration, Policy and Society.

Vincent, L. (2008) The Limitations of 'inter-racial contact': Stories from South Africa Ethnic and Racial Studies 31 (8) 1426-1451

Vulliamy, E. (2005) Rumours of a Riot Guardian Unlimited Special Reports 29 November 2005, www.guardian.co.uk accessed 2.10 .07

Walzer, M. (1995). The Concept of Civil Society in Walzer. M. (Ed) Towards a Global Civil Society. 
Rhode Island: Berghahn Books.

Watson, C. W. (2000). Multiculturalism. Buckingham: Open University Press.

Weisinger, J. Y., Salipante, P.F. (2005). A Grounded Theory for Building Ethnically Bridging Social Capital in Voluntary Organisations Nonprofit and Voluntary Sector Quarterly 34(1): 29-55.

Wilson, M. and Zipfel, T. (2008) Communities R Us: New and Established Communities Working Together London: Housing Associations Charitable Trust (HACT) 